\title{
EPISTEMOLOGIA: UM RECORTE em Pierre Bourdieu
}

\author{
NÉVIO dE CAMPOS \\ Universidade Estadual de Ponta Grossa \\ (UEPG), Ponta Grossa, Paraná, Brasil
}

\begin{abstract}
Resumo: Este artigo discute o problema da epistemologia, recortando sua análise na sociologia da ciência de Pierre Bourdieu. $\mathrm{O}$ percurso parte de uma discussão geral da epistemologia e chega ao posicionamento deste pensador francês, assumindo a hipótese de que a sua sociologia da ciência critica o idealismo e o determinismo científicos e afirma uma leitura de que o campo científico é um produto social, mas com suas especificidades. Apoia-se nos principais escritos deste sociólogo que tratam do problema da ciência, particularmente em Para uma sociologia da ciência e os Usos sociais da ciência: por uma sociologia clínica do campo científico, assim como no aporte teórico da História Intelectual, os quais permitem explicitar a posição desse cientista social, estabelecendo relações entre a obra e seu criador, entre a obra e sua época e entre as diferentes obras da mesma época.

Palavras-chave: Epistemologia. Sociologia da Ciência. Pierre Bourdieu. História Intelectual.
\end{abstract}

\section{NOTAS INTRODUTÓRIAS}

As reflexões a respeito da epistemologia podem ser feitas a partir de áreas distintas e de autores variados. As áreas de Filosofia e Sociologia mostram-se duas possibilidades para problematizar a questão da epistemologia, embora ela não esteja delimitada apenas a tais matrizes disciplinares. Ao dialogar com tais campos de saber, as opções de análises se multiplicam. 
Diante da multiplicidade de possibilidades requer-se que este artigo delimite um recorte analítico. Assim, esta narrativa objetiva transitar entre a Filosofia e a Sociologia, enfatizando um olhar a partir das discussões de Pierre Bourdieu. Ao fazer tal opção, pretende-se partilhar uma alternativa que supere as tentativas consideradas antagônicas: visão essencialista e concepção determinista de ciência. A Filosofia é acusada pela História de tratar as ideias de modo desencarnado. Tal acusação sustenta que a Filosofia compreende as ideias como entes que circulam acima dos indivíduos, dos agentes históricos e concretos. Por outro lado, a Sociologia é acusada de transformar as ideias em meros reflexos da vida social. A visão mais radical da Sociologia, cuja expressão mais destacada está na Sociologia Cognitiva da Ciência, sustenta que os conteúdos científicos são produzidos por meio de causas sociais, portanto, estabelece que as razões epistêmicas seriam vazias idealizações dos filósofos e dos próprios cientistas. Não obstante, o reconhecimento de que a ciência tem uma natureza social implica em poder afirmar que sua explicação não se origina de um campo específico (campo acadêmico/científico)?

Nesse âmbito, o desafio é discutir o problema da epistemologia, na tentativa de sistematizar uma avaliação que busque superar uma visão encantada ou idealista de ciência e uma noção determinista de pesquisa científica, tomando como referência os escritos de sociologia da ciência de Pierre Bourdieu. Tal produção é problematizada sob a perspectiva da História Intelectual, cujo escopo pluridisciplinar (História, Sociologia, Filosofia) permite analisar o funcionamento de uma sociedade intelectual, isto é, "suas práticas, suas estratégias, seus habitus, as características de um momento histórico e conjuntural [...] que impõem visões de mundo, esquemas de percepções e apreciação, enfim, modalidades específicas de pensar e de agir dos intelectuais" (SILVA, 2002, p. 12). Desse modo, a linha interpretativa deste artigo implica em problematizar a posição de Bourdieu a respeito da epistemologia sem deixar de estabelecer relações entre a obra e seu criador, entre a obra e sua época e entre as diferentes obras da mesma época.

\section{NOTAS GERAIS}

A epistemologia é um território de disputa entre os diferentes especialistas. A rigor, suas primeiras discussões sistemáticas remontam aos escritos filosóficos. No campo da Filosofia, a epistemologia assume 
um sentido bastante geral, podendo ser associada à ideia de teoria do conhecimento, caracterizando-se como uma reflexão teórica a respeito das possibilidades e dos limites do conhecimento produzido pela humanidade. Hilton Japiassu (1992, p. 25) corrobora com essa indicação ao dizer que "tradicionalmente, a epistemologia é considerada como uma disciplina especial no interior da Filosofia. Eram os filósofos que faziam as pesquisas em epistemologia. Esta era 'para' a ciência ou 'sobre' a ciência, mas não era obra dos próprios cientistas".

A definição do que seja epistemologia não é tarefa fácil, pois as conceituações divergem de acordo com as perspectivas adotadas. Para Japiassu (1992, p. 24) '"epistemologia' significa, etimologicamente, discurso (logos) sobre a ciência (episteme). Apesar de parecer um termo antigo, sua criação é recente, pois surgiu a partir do século XIX no vocabulário filosófico". Essa dupla condição obriga "que se compreenda como a epistemologia se situa a si mesma relativamente à filosofia das ciências e a outras disciplinas que lhe são mais ou menos afins" (JAPIASSU, 1992, p. 29), ou melhor, que a epistemologia seja situada "na intersecção de preocupações e de disciplinas bastante diversas, tanto por seus objetivos quanto por seus métodos" (JAPIASSU, 1992, p. 29). Por um lado, seguindo Japiassu (1992, p. 24), "podemos confinar a epistemologia, desde o início, nos limites do discurso filosófico, fazendo dela uma parte deste discurso. Foi assim que fizeram todas as epistemologias tradicionais, chamadas de filosofia das ciências ou de teoria do conhecimento". Por outro, "caracterizaremos a epistemologia como um discurso sobre o qual o discurso primeiro da ciência deveria ser refletido" (JAPIASSU, 1992, p. 24). Desse modo, sustenta Japiassu (1992, p. 24), "o estatuto do discurso epistemológico, como duplo, é ambíguo: discurso sistemático que encontraria na filosofia seus princípios e na ciência seu objeto. Seria um discurso dividido entre duas formas de discurso racional".

Esse significado enunciado nessas linhas iniciais pode ser observado na compreensão que Nicola Abbagnano estabelece ao registrar o verbete epistemologia em seu Dicionário de Filosofia e ao remeter o leitor ao termo teoria do conhecimento. As observações de Abbagano indicam que teoria do conhecimento em inglês denomina-se, em geral, como epistemology; já, em alguns casos, como gnosiology. Na cultura francesa acontece o contrário, pois em regra usa-se gnoséologie e, em casos específicos, epistemologie. $\mathrm{Na}$ tradição germânica, gnoseologie raramente é utilizada, sendo muito comum erkenntnistheorie. Já na experiência italiana destaca-se o uso de toeria dela concoscenza e de gnoselogie; em escala muito reduzida aparece epistemologia. 
Embora essas diferentes terminologias, "todos esses nomes têm o mesmo significado: não indicam, como muitas vezes se crê ingenuamente, uma disciplina filosófica geral, como a lógica, a ética ou a estética, mas um modo de tratar um problema nascido, no âmbito de determinada corrente filosófica, que é o idealismo" (ABBAGNANO, 2003, p. 183).

As reflexões de Abbagnano tratam de incluir a teoria do conhecimento no âmbito da Filosofia, demarcando também os desdobramentos com o processo de constituição de inúmeras áreas do campo científico. Em primeiro lugar, ele (2003, p. 183) assevera que a teoria do conhecimento funda-se em dois pressupostos. Por um lado, apoia-se na assertiva de que "o conhecimento é uma 'categoria' do espírito, uma'forma' da atividade humana ou do'sujeito". Por outro, apregoa que "o objeto imediato do conhecimento é, como acreditava Descartes, apenas a ideia ou a representação". Nesse sentido, a discussão da teoria do conhecimento seria perscrutar"se a essa ideia corresponde uma coisa qualquer, ou entidade 'externa'; no caso de uma resposta negativa, existe alguma diferença, e qual, entre ideias irreais ou fantásticas e ideias reais" (ABBAGNANO, 2003, p. 183).

O debate em torno da ciência ganhou dimensões ampliadas a partir do século XIX. No século XX inúmeros especialistas ocuparam a cena para participar desse debate, o que torna hercúlea qualquer tentativa de organizar uma síntese. Japiassu (1992, p. 29) afirma ser "muito difícil encontrar uma lista completa e precisa dessas disciplinas", limitando-se a discutir algumas (filosofia da ciência, história da ciência, psicologia da ciência e sociologia da ciência), ficando a encargo do leitor consultar outras obras, como, por exemplo, Abbagnano (2003), Blanché (1987), Gamboa (2007), Japiassu (1986; 1992) que abordam esse tema.

É importante destacar que para Bourdieu (2008b, p. 19), "o campo das disciplinas e dos agentes que tomam a ciência como tema - filosofia das ciências, epistemologia, história das ciências, sociologia das ciências -, campo de fronteiras mal definidas, é atravessado por controvérsias e conflitos". Além disso, ele destaca (2008b, p. 19) que"por ser suposto tratar de problemas últimos e se situar na ordem do meta, do reflexivo, ou seja, no corolário ou no fundamento, o campo é dominado pela Filosofia, cujas ambições de grandeza ele imita". O pensamento de Bourdieu (2008b, p. 21) assinala a dificuldade de estabelecer uma história da própria sociologia da ciência, "[...] não só por causa do volume da produção escrita, mas também pelo facto de a sociologia da ciência ser um campo em que a história da disciplina é uma questão de lutas (entre outras)". 
Nessas notas gerais, a pretensão foi indicar ao leitor alguns aspectos que circulam pelo debate da epistemologia. A ideia foi destacar que a epistemologia é uma arena de disputa entre os mais variados especialistas, assim como explicitar que os sentidos do que seja epistemologia sofrem alterações. Assim sendo, as páginas seguintes verticalizam a discussão com o objetivo de sistematizar e sintetizar a posição de Pierre Bourdieu nesse debate.

NOTAS HISTÓRICAS

A epistemologia é um espaço de luta pelo direito de definir o que ela seja. Se a tarefa de retratar esta disputa é bastante difícil e não factível de fazer no formato de um artigo, o esforço de revisitar as obras de Bourdieu que tratam do problema da ciência mostra-se possível. Assim, verticalizamos esta análise a fim de mostrar os combates da sociologia desse pensador francês, recuperando o contexto e os sentidos da sua sociologia da ciência.

Há inúmeros textos que retratam a trajetória intelectual de Bourdieu, entre eles destacamos aqueles que estão à disposição do leitor brasileiro: Bonnewtiz (2003), Catani (1999), Nogueira e Nogueira (2009), Ortiz (2002; 2003), Vasconcelos (2002), Wacquant (2002). Os escritos de Bourdieu são variados, pois conforme apresentação de Patrick Champagne (2004, p. 7), ele “[...] estudou quase tudo: os camponeses, os artistas, a escola, os clérigos, os patrões, as classes populares etc.". Além do mais, Champagne (p. 7) ressalta que os estudos de Bourdieu abarcam disciplinas como "[...] a etnologia, a sociologia, a filosofia, a sociolinguística, a economia, a história etc.".

A principal tarefa heurística é como articular um agente aos múltiplos fatores sociais, pois aqui reside a forma de olhar e interpretar o lugar de um indivíduo na história. Bourdieu é um intelectual do século XX, com sua trajetória demarcada por profunda inserção no campo acadêmico das ciências sociais. Essa observação pode ser mais bem compreendida à luz da assertiva de Renato Ortiz (2003, p. 9) quando afirma que Bourdieu, ao ler Durkheim, sublinhou a seguinte passagem de As Regras do Método Sociológico:"acreditamos que chegou o momento para a Sociologia de renunciar aos sucessos mundanos, de tomar o caráter esotérico que convêm a toda ciência. Ela ganhará assim em dignidade e autoridade o que certamente perderá em popularidade". É muito revelador este fragmento apropriado por Bourdieu, uma vez que dá alguns sinais para interpretar a trajetória desse pensador 
francês e elucidar os combates que ele travou em defesa da legitimidade do discurso das ciências sociais. Esse aspecto pode ser corroborado com a afirmação de Sergio Miceli (1999, p. 108) de que "a tradição francesa em Sociologia e Antropologia é indissociável do nome de Durkheim, da herança intelectual do grupo sob sua liderança".

A trajetória de Bourdieu está demarcada pela incursão em inúmeras instituições universitárias, na criação de revistas e centros de pesquisa e publicação de centenas de artigos e livros. Em 1964 ingressou na Escola de Altos Estudos em Ciências Sociais e, em 1981, no Colégio da França, tornando-se titular da cadeira de sociologia. A rigor, "a nomeação de Bourdieu para o Collège de France, traduz não apenas a sua consagração, mas também o seu apogeu" (BONNEWITZ, 2003, p. 17). De acordo com Miceli (1999, p. 117), o Colégio da França:

Oferece ao intelectual ungido uma cátedra modular, adaptável aos riscos de sua invenção, um lugar dotado de autoridade e, ao mesmo tempo, apto a garantir a expressão refinada de especialistas anfíbios, habituados a testar os resultados da convivência entre as artes, as literaturas, as filosofias e as ciências humanas.

Bourdieu participou do processo de constituição do campo científico da sociologia na França, estabelecendo os cursos de graduação e definindo um lugar a essa área do conhecimento em diferentes instâncias do ensino francês. Nesse movimento, "enquanto muitos de seus colegas pensadores evocavam uma sociologia em estado de crise, Pierre Bourdieu reconhece sua importância e acredita que ela pode ser elevada a um alto grau de cientificidade e de objetividade" (VALLE, 2007, 119). No capítulo intitulado "Como se tornar um sociólogo?" Patrice Bonnewitz sintetiza o contexto de formação acadêmica e intelectual de Bourdieu, assim como destaca a relação que ele estabeleceu com os clássicos da sociologia. Nesse aspecto, Bonnewitz (2003, p. 26) sustenta que"se há uma característica que convém ressaltar na formação de Bourdieu é a multiplicidade das influências que ele sofreu". Entretanto, "sua obra também é produto de uma releitura crítica dos questionamentos antropológico e sociológico tradicionais. Esta vontade de ruptura e de superação deu origem, assim, ao estruturalismo genético" (BONNEWITZ, 2003, p. 26). Bonnewitz indica a filiação de Bourdieu ao estruturalismo genético, aliás, classificação consentida pelo próprio sociólogo meio a contragosto, pois asseverou que "se eu gostasse do jogo dos rótulos, que é muito praticada no campo intelectual desde que certos filósofos introduziram nele as modas e 
os modelos do campo artístico, eu diria que tento elaborar um estruturalismo genético" (BOURDIEU, 2004, p. 26).

Além de suas inúmeras produções sociológicas, ele escreveu reflexões a respeito do próprio campo científico, na tentativa de objetivar o sujeito da objetivação. Assim, no conjunto de sua produção estão seus escritos que tratam especificamente do campo científico, a saber: Le métier de sociologue: préalables épistémologiques [Ofício de sociólogo: metodologia da pesquisa na sociologia] (1968) ${ }^{1}$ (La spécificité du champ scientifique et les conditions sociales du progrès de la raizon [A especificidade no campo científico e as condições sociais do progresso da razão] (1975), Le champ sceientifique (1976), Les usages sociaux de la science: por une sociologie clinique du champ scientific [Os usos sociais da ciência: por uma sociologia clínica do campo científico] (1997) e Science de la science et refléxivité [Para uma sociologia da ciência] (2001). ${ }^{3}$ Essas produções específicas sobre o campo científico guardam uma relação com a ideia-força de todas as obras de Bourdieu. Conforme lone Ribeiro Valle (2007, p. 119), “[...] a sociologia de Bourdieu cresceu em torno de uma intuição, uma idéia-força, que ele desenvolveu, repetiu, reformulou e aplicou em diferentes problemáticas. Essa intuição fundadora pode ser resumida em uma fórmula única: 'as idéias puras não existem'"'.

Imbuídos dessa assertiva destacada por lone Valle, promovemos uma interlocução com as reflexões de Bourdieu, sistematizadas naquelas obras indicadas acima. Há longo intervalo, entre os três primeiros escritos e os dois últimos, pois aqueles remontam aos anos de 1968/1975/1976. O penúltimo é resultado da conferência proferida no Institut National de la Recherche Agronomique de Paris (INRA) [Instituto Nacional da Pesquisa Agronômica] no dia 11 de março de 1997, publicado em forma de livro no mesmo ano na França e traduzido no Brasil em 2004. O último é decorrente do seminário ministrado no Colégio da França em 2000/2001 e publicado em forma de livro na França em 2001 e traduzido em Portugal no ano de 2008. Os dois últimos indicam uma atualização do pensamento de Bourdieu a respeito dos problemas epistemológicos. Em razão disso, optamos por dialogar de modo mais preciso com o livro Para uma sociologia da ciência. Há uma razão muito forte em privilegiar essa obra, pois é oriunda da maturidade intelectual de Bourdieu. Além do mais, materializa uma confrontação às correntes em marcha naquele momento, pois conforme Bonnewitz (2003, p. 17), "a década de 80 assinala o forte retorno das teorias do ator e do individualismo metodológico. A primeira metade da década de 90 privilegia a abordagem etnometodológica, de inspiração americana". A rigor, a etnometodologia "[...] 
centra o seu interesse no conhecimento ordinário dos membros de uma sociedade, nas rotinas e percepções que eles mobilizam em sua vida cotidiana" (BONNEWITZ, 2003, p. 17).

Estas discussões de Bourdieu devem ser compreendidas no interior do campo acadêmico, pois há uma profunda intenção em problematizar as posições do que ele denomina de uma visão logicista de ciência e de concepção desencantada de pesquisa científica. Por outro lado, há uma preocupação mais ampla nesta análise empreendida por este sociólogo francês, pois ele (2008b, p. 7) sustenta que decidiu tomar a ciência como tema de discussão no ano letivo 2000-2001 do Colégio da França e publicar em forma de livro porque entende "[...] que o universo da ciência está hoje ameaçado por uma terrível regressão. A autonomia que, a pouco e pouco, a ciência conquistou aos poderes religiosos, políticos ou até mesmo econômicos está muito enfraquecida". Bourdieu (2008b, p. 7) avança em sua análise ao dizer que "a submissão aos interesses económicos e às seduções mediáticas ameaça juntar-se às críticas externas e às difamações internas - são certos delírios 'pós-modernos' - para minar a confiança na ciência e, especialmente, na ciência social". Mais à frente ele sintetiza o objetivo de organização da obra Para uma sociologia da ciência:

Foi por isso que me pareceu particularmente necessário submeter a ciência a uma análise histórica e sociológica que não visa de modo algum relativizar o conhecimento científico confrontando-o e reduzindo-o às suas condições históricas, portanto, a circunstâncias localizadas e datadas, mas que pretende, muito pelo contrário, fazer com que os cientistas compreendam melhor os mecanismos sociais que orientam a prática científica e se tornem assim "donos e senhores" não só da "natureza", segundo a velha ambição cartesiana, mas também, e não há dúvida de que não é menos difícil, do mundo social em que se produz o conhecimento da natureza. (BOURDIEU, 2008b, p. 9).

Em síntese, este item buscou trazer alguns elementos para compreender a inserção de Pierre Bourdieu no campo acadêmico francês. Sem dúvida que a forma estenográfica dessa narrativa deixa muitas lacunas. Não obstante, a preocupação consistiu em descrever alguns aspectos da trajetória deste sociólogo, destacando sua movimentação no campo acadêmico ao integrar universidades e o Colégio da França, assim como em publicar centenas de obras. Em sentido preciso, buscou-se trazer informações para assinalar as relações entre a obra e seu autor, entre a obra e sua época e entre as diferentes obras da mesma época. 


\section{NOTAS TEÓRICAS}

As ideias são fundamentais para compreender as posições teóricas de Bourdieu. No entanto, os textos em si não dão conta da totalidade dos sentidos contidos neles mesmos. Nesse aspecto, é importante reportar-se ao próprio sociólogo quando em A economia das trocas linguísticas (2008a, p. 85-96) assinala a importância de problematizar três instâncias da formação discursiva: De onde diz? Para quem diz? E o que diz? Em certo sentido, o item notas históricas procurou indicar algumas chaves de leituras para compreender o lugar de onde Bourdieu profere suas reflexões, assim como a quem endereça suas discussões. Essas três instâncias são indissociáveis, pois permitem elucidar o lugar do autor em relação a sua época e aos seus interlocutores.

A abordagem da ciência promovida por Bourdieu tem caráter histórico e sociológico. Nesses termos, toma a ciência como um produto social e temporal. Na introdução do livro Para uma sociologia da ciência, as indagações deste sociólogo são diversas, entre elas destacamos (2008b, p. 13): "será possível fugir à alternativa do logicismo e do relativismo que é por certo apenas uma variante da velha controvérsia entre o dogmatismo e o cepticismo?" Alguns dos representantes da posição logicista, cunhada por Bourdieu (2008b, p. 13), seriam Frege e Russel, cuja tese consiste em sustentar que "[...] há regras gerais a priori para a avaliação científica e um código de leis imutáveis para distinguir a boa da má ciência". A contraposição a esta visão idealista está em Bachelard, um dos principais epistemólogos utilizado por Bourdieu para sistematizar sua sociologia da ciência. Bachelard, segundo Bourdieu (2008b, p. 13), "já observava que a epistemologia tinha reflectido demais sobre as verdades da ciência estabelecida e não o suficiente sobre os erros da ciência que se faz, sobre a atividade científica tal como se apresenta". Por outro lado, no campo das ciências sociais, inúmeros autores fizerem frente a outra direção epistemológica. Na interpretação deste sociólogo francês (2008b, p. 13), os pensadores sociais "abriram a caixa de Pandora, o laboratório, e esta exploração do mundo científico tal como se apresenta fez aparecer todo um conjunto de factos que colocam fortemente em causa a epistemologia científica de tipo logicista". Em outra posição (2008b, p. 13), "a visão realista, e em geral desencantada, que deram assim das realidades do mundo científico levou-os a propor teorias relativistas, e até niilistas, que se opõem à representação oficial da ciência".

"Um mundo à parte" é o título do segundo capítulo do livro Para uma sociologia da ciência. Explicitar o sentido da sentença do título do capítulo 
é a preocupação de Bourdieu. Sua posição parte da explicação do uso do conceito de campo que "[...] coloca a tónica nas estruturas que orientam as práticas científicas e cuja eficácia se exerce à escala microssociológica em que se situa a maior parte dos trabalhos que critiquei, e em especial os estudos de laboratório" (BOURDIEU, 2008b, p. 51). Não é possível compreender o domínio da ciência tomando as representações e as práticas dos pesquisadores de modo desarticulado das forças constituídas no campo científico. Este sociólogo (2008b, p. 51) descaracteriza as análises que estão recortadas em objetos, "[...] micro-unidades sociais consideradas autónomas, universos isolados e circunscritos que se pensava ser mais fáceis de estudar porque os dados se apresentavam de alguma forma já preparados a essa escala". Essa tendência analítica é identificada nos estudiosos das microssociologias, para os quais, segundo Bourdieu (p. 51), "o laboratório, pequeno universo fechado e isolado, que elabora relatórios para análise e registros, parece, do mesmo modo, invocar semelhante abordagem monográfica e ideográfica". Essa crítica já estava presente na obra Ofício de Sociólogo (1968) quando Bourdieu contrapôs-se ao movimento da sociologia empírica advinda dos Estados Unidos no pós-Segunda Guerra. Naquele momento, ele destacava que "toda comunidade erudita é um microcosmo social, dotado de instituições de controle, de exigências e de formação, autoridades universitárias, etc., que definem as normas da competência profissional e tendem a inculcar os valores que elas exprimem" (BOURDIEU; CHAMBOREDON; PASSERON, 2007, p. 94).

É importante chamar a atenção da forma como Bourdieu reflete a respeito do uso do conceito de campo em suas investigações. No capítulo "A gênese dos conceitos de habitus e de campo" da obra O poder simbólico, imediatamente assevera que "a teoria científica apresenta-se como um programa de percepção e de acção só revelado no trabalho empírico em que se realiza". Em outras palavras, a construção teórica é uma produção "provisória elaborada para o trabalho empírico e por meio dele, ganha menos com a polémica teórica do que com a defrontação com novos objetos" (BOURDIEU, 2002, p. 59). Esses dois fragmentos indicam que a construção teórica perpassa inexoravelmente pela prática da pesquisa, isto é, não é possível determinar os quadros teóricos sem uma movimentação permanente de cotejamento com os dados empíricos. Nesse âmbito está o sentido do conceito de campo. Essa noção, segundo Bourdieu (2002, p. 64), "[...] serviu primeiro para indicar uma direção à pesquisa, definida negativamente como recusa à alternativa da interpretação interna e da explicação externa, perante a qual se achavam colocadas todas as ciências das obras culturais, ciências religiosas, história da arte". Na sequência ele (2002, p. 65-66) indica que "para construir a noção 
de campo, foi preciso passar para além da primeira tentativa de análise do 'campo intelectual' como universo relativamente autônomo de relações específicas". Isso quer dizer que "as relações imediatamente visíveis entre os agentes envolvidos na vida intelectual tinham disfarçado as relações objetivas entre as posições ocupadas por esses agentes, que determinam as formas de tais interacções" (2002, p. 66). Este conceito permite uma dupla crítica, seja aos defensores das vertentes interacionistas oriundas da fenomenologia ou aos adeptos dos mais variados determinismos. Nesse aspecto, o desafio do pesquisador, segundo este cientista social (2002, p. 69) está na condição de que "compreender a génese social de um campo, e apreender aquilo que faz a necessidade específica da crença que o sustenta, do jogo de linguagem que nele se geram, é explicar, tornar necessário, subtrair ao absurdo do arbitrário e do não-motivado os actos dos produtores e as obras por eles produzidas".

Na obra Para uma sociologia da ciência ele explicita a crítica à operação das microssociologias quando analisa o campo científico. Para ele (2008b, p. 51-52),

O laboratório é um micro-cosmo social situado num espaço que abrange outros laboratórios constitutivos de uma disciplina (ela própria situada num espaço, também hierarquizado, de disciplinas) e deve uma parte muito importante das suas características à posição que ocupa nesse espaço.

Por outro lado, assevera (2008b, p. 52) que apenas "uma teoria global do espaço científico, como espaço estruturado segundo lógicas simultaneamente genéricas e específicas, permite compreender realmente um determinado ponto deste espaço, laboratório ou investigador particular". Bourdieu (2008b, p. 52) avança em sua análise ao reiterar que o conceito de campo produz uma ruptura com a "visão interacionista pelo facto de levar em conta a existência da estrutura de relações objectivas entre os laboratórios e entre os investigadores que comanda ou orienta as práticas". Além disso, destaca (2008b, p. 52) que faz uma segunda ruptura "porque a visão relacional ou estrutural que introduz se associa a uma filosofia disposicionalista de acção que rompe com o finalismo, correlativo de um intencionalismo ingênuo".

É importante informar ao leitor que, no seminário apresentado no Colégio da França nos anos 2000/2001, Bourdieu recupera a discussão estabelecida no artigo La spécificité du champ scientifique et les conditions sociales du progrès de la raizon de 1975. Ele reafirma que, neste artigo, propôs "a ideia de que o campo científico, tal como outros campos, é um campo de forças dotado de uma estrutura e também um espaço de conflitos pela manuten- 
ção ou transformação desse campo de forças" (BOURDIEU, 2008b, p. 52). Há uma dupla constituição do campo científico. De um lado, aquilo que o autor denomina de física social, a parte dura da organização desse espaço social. De outro, o domínio dos possíveis, isto é, as condições criadas pelos agentes para manter ou alterar as relações existentes no campo acadêmico. $O$ desafio está que toda análise do campo científico considere esse espaço social como relacional, isto é, constituído a partir de relações travadas entre os agentes (indivíduos e/ou instituições) em determinadas condições objetivas existentes. Operam-se no interior do campo acadêmico relações demarcadas pelo campo de poder, cujas relações de forças "entre as posições sociais garantem aos seus ocupantes um quantum suficiente de força social - ou de capital - de modo a que estes tenham a possibilidade de entrar nas lutas pelo monopólio do poder" (BOURDIEU, 2002, p. 29). Assim, ele sustenta (2002, p. 31), "se é verdade que o real é relacional, pode acontecer que eu nada saiba de uma instituição acerca qual eu julgo saber tudo, porque ela nada é fora das suas relações com o todo".

Seguindo a leitura de Roger Chartier (2002a, p. 140), destacamos que:

A idéia do pensamento relacional permite, ao mesmo tempo, repelir a idéia do indivíduo isolado, do gênio singular e também a idéia de uma universalidade das categorias que espontaneamente se utilizam para pensar, discutir, qualificar as obras intelectuais ou estéticas.

Desse modo, uma análise relacional do campo acadêmico está associada ao fato de "não ser possível apreender os espaços sociais de outra forma que não seja a de distribuições de propriedades entre indivíduos" (BOURDIEU, 2002 , p. 29). Propriedades entre indivíduos tanto podem estar relacionadas aos pesquisadores como às instituições de pesquisa que compõem o campo científico. Nesses termos, segundo Bourdieu (2008b, p. 53), "a força de um agente depende dos seus diferentes trunfos, factores diferenciais de sucesso que podem garantir-lhe uma vantagem em relação aos rivais, ou seja, depende do volume e estrutura do capital de diferentes espécies que possui". Esse aspecto está articulado ao segundo sentido do conceito de campo, como espaço de conflito, "como campo de acção socialmente construído em que os agentes dotados de diferentes recursos se defrontam para conservar ou transformar as relações de força vigentes". De modo mais refinado, conforme Bourdieu (2008b, p. 54), "os agentes empreendem aqui acções que dependem, nos seus fins, meios e eficácia, da sua posição no campo de forças, ou seja, da posição na estrutura da distribuição do capital". 
Esta discussão remete ao conceito de habitus na teoria social de Bourdieu, pois estaríamos tratando da história incorporada pelos agentes e da história objetivada nas estruturas do campo científico. Esse processo disposicional dos agentes é debatido por Bourdieu sob a denominação de o ofício do cientista. Para Bourdieu (2008b, p. 58), "a noção de habitus é, talvez, útil quando se trata de compreender a lógica de um campo como o campo científico em que a ilusão escolástica se impõe com uma força particular". Esta visão escolástica, destacada pelo sociólogo francês, tem relação orgânica com a compreensão logicista de ciência, pois apregoa um entendimento do que ele chama de opus operatum, isto é, de ciência acabada. Por outro lado, ele apregoa a ideia de modus operandi (modo de funcionamento) do campo científico.

Em O poder simbólico, no capítulo que trata da origem dos conceitos de campo e habitus, Bourdieu (2002, p. 61) destaca que "a noção de habitus exprime sobretudo a recusa a toda uma série de alternativas nas quais a ciência social se encerrou, a da consciência (ou do sujeito) e do inconsciente, a do finalismo e do mecanicismo, etc.." Ele admite (2002, p. 61) que "tal noção permitia-me romper com o paradigma estruturalista sem cair na velha filosofia do sujeito ou da consciência, a da economia clássica e do seu homo economicus que regressa hoje com o nome de individualismo metodológico". De outro modo, ele ressalta (2002, p. 61) que "desejava pôr em evidência as capacidades 'criadoras', activas, inventivas, do habitus e do agente, embora chamando a atenção para a ideia de que esse poder gerador não é de um espírito universal, de uma natureza ou de uma razão universal". Ao contrário, "o habitus é um conhecimento adquirido e também um haver, um capital". Ou ainda,"o hatitus, a hexis, indica a disposição incorporada, quase postural -, mas o de um agente em acção" (BOURDIEU, 2002, p. 61). Nesse sentido, assevera (2008b, p. 59) que"reintroduzir a ideia de habitus remete as práticas científicas, não para o princípio de uma consciência cognitiva que age de acordo com as normas explícitas da lógica e do método experimental, mas para a ideia de 'ofício', ou seja, um sentido prático dos problemas a tratar". Ele (2008b, p. 61) avança ao dizer que "o campo científico é, tal como outros campos, o lugar de lógicas práticas, mas com a diferença de o habitus científico ser uma teoria realizada, incorporada". O leitor pode acompanhar, na obra Ofício de Sociólogo, escrita por Bourdieu, Chamboredon e Passeron, a sistematização da discussão acerca das especificidades do processo de conhecimento na área das ciências humanas e sociais.

Esses dois conceitos permitem a Bourdieu indicar certa regularidade do campo científico. Entretanto, o analista do campo científico precisa ficar atento, 
pois esta regularidade deve ser tomada como hipótese, pois em cada sociedade suas peculiaridades, assim como as variáveis se diferenciam nas temporalidades diversas. Nesse sentido, vejamos o comentário de Chartier (2002, p. 146):

[...] O mais importante é trabalhar com Bourdieu, quer dizer, é utilizá-lo para temas que não pôde abordar, para períodos que não foram historicamente os mais importantes para ele. Trabalhar com seus conceitos, mas ir além, trabalhar com as suas perspectivas, com a idéia de um pensamento relacional e a repulsa à projeção universal de categorias historicamente definidas.

As notas teóricas de Bourdieu são oriundas de suas pesquisas nas mais variadas temáticas. Nesse item, privilegiamos um olhar a respeito de suas anotações sobre o campo científico. Porém, destacamos que ele produziu uma série de análises das instituições acadêmicas da França, buscando estabelecer esta relação necessária entre os aportes teóricos e as experiências históricas dos agentes sociais envolvidos no espaço científico, como, por exemplo, em As regras da arte e Homo academicus. Assim, os operadores dos conceitos bourdieusianos devem estar atentos ao que ele $(1996$, p. 7$)$ fazia questão de alertar: "eu não gostaria de ser lido como um 'teórico' puro: os conceitos que proponho não são o produto de uma partenogênese teórica e foram todos construídos, com frequência, ao preço de um grande esforço, para resolver problemas inseparavelmente empíricos e teóricos". Logo, as notas teóricas são lidas na relação com as notas históricas da trajetória deste sociólogo contemporâneo.

\section{NOTAS FINAIS}

A narrativa deste artigo está assentada nos aportes analíticos da História Intelectual, na qual não há um consenso nos modos de tratar seu objeto. No entanto, a abordagem assumida compartilha de que não é possível praticar uma análise das obras, do pensamento e de um autor ao modo da clássica história das ideias ou da história da filosofia. Assim, em consonância com Chartier (2002b, p. 28), buscou-se evitar"[...] isolar as ideias ou os sistemas de pensamento das condições que autorizam sua produção, por separá-los radicalmente das formas da vida social". Ou melhor, evitar a praticar "[...] essa história desencarnada [que] institui um universo de abstrações onde o pensamento parece não ter limites já que não tem dependências" (CHARTIER, 2002b, p. 28). Além disso, não partilhamos da hipótese de que "a uma história intelectual das inteligências sem limites e das ideias sem suporte, é 
oposta uma história das representações coletivas, das aparelhagens e das categorias intelectuais disponíveis em uma época dada" (CHARTIER, 2002b, p. 33). Nesses termos, de um lado advertimos que "a história das ideias [...] pende demais para a intelectualidade pura". Por outro, asseveramos quanto ao risco oposto ao sustentar-se "[...] o que importa, tanto quanto a ideia talvez mais, é a encarnação da ideia, suas significações, o uso que se faz dela" (CHARTIER, 2002b, p. 42).

A produção de Bourdieu pretendia combater essas duas tradições interpretativas dos bens culturais. Em específico, contrapôs-se ao movimento presente nas leituras sistematizadas a respeito do campo científico. Desse modo, este texto procurou dar visibilidade ao mesmo tempo às obras, ao seu autor e ao contexto de produção, relativizando leituras que privilegiam apenas os textos (abordagem internalista) ou somente as redes de sociabilidade (abordagem externalista). Em termos mais precisos, este artigo pautou-se na hipótese de que "a produção e a recepção de uma obra são resultantes de 'campos' intelectuais nacionais respectivos e de sistemas distintos de percepção e de pensamento que eles impõem e inculcam" (SILVA, 2002, p. 12-13).

Sob a inspiração desta discussão foi construída a análise do problema da epistemologia. A primeira medida foi indicar que a epistemologia é um objeto de debate e disputa entre os mais variados especialistas, sem nenhuma pretensão de sustentar a quem está reservado o direito de dizer o que é epistemologia. $\mathrm{O}$ ato seguinte tratou de introduzir Pierre Bourdieu, nesse debate, adentrando especificamente no objetivo central deste artigo. Assim sendo, Bourdieu passou a ser representado no ambiente intelectual do século $X X$, particularmente na esfera do campo acadêmico/científico da França da segunda metade dos novecentos. A ideia foi mostrar como este autor circulou entre os mais variados ambientes intelectuais e estabeleceu um conjunto de estratégias para transformar seu discurso em linguagem autorizada. Pode-se dizer que as notas históricas trataram de criar esse efeito de sentido, isto é, de devolver o indivíduo à sua época, na tentativa de articular autor e obras, autor e contexto. Por fim, o quadro interpretativo de Bourdieu não poderia eclipsar as próprias ideias refletidas por ele, pois elas representam o momento de criação deste sociólogo, o instante em que ele sistematiza a sua interpretação das discussões existentes na área da epistemologia e apresenta a contribuição, nesse movimento, de disputa pela legitimidade de um discurso sobre o campo científico.

Este exercício analítico fez dois movimentos. De um lado, procurou produzir uma interpretação do problema da epistemologia a partir de Pierre 
Bourdieu, na tentativa de estabelecer uma demarcação da posição da sociologia do conhecimento no âmbito da epistemologia. Por outro, buscou indicar a fecundidade das reflexões deste sociólogo à organização de estudos que tratam do campo científico/acadêmico. O primeiro aspecto ganhou maior espaço, pois a narrativa buscou mostrar o lugar social de Bourdieu no âmbito desse debate. $O$ segundo movimento recebeu menor atenção, embora ao discutir algumas das contribuições deste sociólogo à epistemologia, chamamos atenção de que é preciso utilizar os conceitos de Bourdieu para problematizar o processo de formação do campo científico em lugares e contextos que não estavam presentes em suas análises. Ou seja, é fundamental que os pesquisadores considerem a assertiva de Renato Ortiz $(2002$, p. 10) ao sustentar que "Bourdieu tem razão quando diz que a história das ideias não se resume apenas às ideias; é preciso, ainda, compreender como elas são trabalhadas pela comunidade acadêmica, pelo'campo científico'. Este é o nicho no qual as abstrações se atualizam". Esta observação de Ortiz tem correspondência com a reflexão de Chartier, de modo particular, quando ele assinala que o uso do pensamento relacional e a repulsa a tentativa de universalização de categorias particulares, constituem as principais instigações aos novos estudos, isto é, constituem os desafios de pensar com e a partir de Bourdieu.

Artigo recebido em: 22/06/2015 Aprovado para publicação em: 14/11/2015

\section{EPISTEMOLOGY: AN OVERVIEW OF PIERRE BOURDIEU}

ABSTRACT: This article discusses the problem of epistemology, analyzing the sociology of science by Pierre Bourdieu. It begins with a general discussion on epistemology and then approaches the point of view of this French thinker, adopting the hypothesis that his sociology of science criticizes scientific idealism and determinism and affirms an understanding that the scientific field is a social product, but with its specificities. It bases itself on the main writings of this sociologist which deal with the problem of science, especially in For a Sociology of Science and Social Uses of Science: for a clinical sociology in the scientific field, in the same way as in the theoretical input of Intellectual History, which explains the thinking of this social scientist, establishing links between the work and its creator, between the work and its epoch and among the different works of the same period.

KEYWORDS: Epistemology. Sociology of science. Pierre Bourdieu. Intellectual History. 


\section{EPISTEMOLOGÍA: UN RECORTE EN PIERRE BOURDIEU}

RESUMEN: Este artículo discute el problema de la epistemología, recortando su análisis en la Sociología de la Ciencia de Pierre Bourdieu. El itinerario parte de una discusión general de la epistemología y llega hasta el posicionamiento de este pensador, asumiendo la hipótesis de que su sociología de la ciencia critica el idealismo y el determinismo científicos y afirma una lectura de que el campo científico es un producto social, pero con sus especificidades. Se apoya en los principales escritos de este sociólogo que tratan el problema de la ciencia, particularmente en "Para uma sociologia da ciência y los Usos sociais da ciência: por uma sociologia clínica do campo científico", así como en el aporte teórico de la Historia Intelectual, los cuales permiten explicitar la posición de ese cientista social, estableciendo relaciones entre la obra y su creador, entre la obra y su época y entre las diferentes obras de la misma época.

Palabras-claves: Epistemología. Sociología de la Ciencia. Pierre Bourdieu. Historia Intelectual.

\section{NOTAS}

1) publicado em francês em 1968.

2) publicado em francês em 1997.

3) publicado em francês em 2001.

\section{REFERÊNCIAS}

ABBAGNANO, N. Dicionário de filosofia. São Paulo: Martins Fontes, 2003.

BLANCHÉ, R. A epistemologia. Lisboa: Presença, 1983.

BONNEWITZ, P. Primeiras lições sobre a sociologia de P. Bourdieu. Petrópolis: Vozes, 2003.

BOURDIEU, P. A economia das trocas linguísticas: o que falar quer dizer. São Paulo: EDUSP, 2008a.

As regras da arte: génese e estrutura do campo literário. Lisboa: Estampa, 1996.

Coisas ditas. São Paulo: Brasiliense, 2004.

Homo academicus. Florianópolis: UFSC, 2013.

. La spécificité du champ scientifique et les conditions sociales du progrès de la raizon. Sociologie et sociétés, n. 1, p. 91-118, maio 1975. 
Le champ sceientifique. Actes de la Recherce em Sciences Sociales, n. 2/3, p. 88-104, jun. 1976.

Para uma sociologia da ciência. Lisboa: Edições 70, 2008b.

. O poder simbólico. Rio de Janeiro: Bertrand Brasil, 2002.

. Os usos sociais da ciência: por uma sociologia clínica do campo científico. São Paulo: UNESP, 2004.

Razões práticas: sobre a teoria da ação. Campinas: Papirus, 1996.

BOURDIEU, P.; CHAMBOREDON, J-C.; PASSERON, J-C. Ofício de sociólogo: metodologia da pesquisa na sociologia. Petrópolis: Vozes, 2007.

CATANI, A. M. Algumas lições da aula inaugural de Pierre Bourdieu. In: CATANI, A. M.; MARTINEZ, P. H. (Org.). Sete ensaios sobre o Collège de France. São Paulo: Cortez, 1999, p. 89-104.

CHAMPAGNE, P. Prefácio. In: BOURDIEU, P. Os usos sociais da ciência: por uma sociologia clínica do campo científico. São Paulo: UNESP, 2004, p. 7-15.

CHARTIER, R. História intelectual e história das mentalidades. In: À beira da falésia: a história entre incertezas e inquietude. Porto Alegre: UFRGS, 2002b, p. 23-60.

Pierre Bourdieu e a história: Roger Chartier debate com José Sérgio Leite Lopes. Topoi, Rio de Janeiro, n. 4, p. 139-182, jan./jun. 2002a.

GAMBOA, S. S. Pesquisa em educação: métodos e epistemologia. Chapecó: Argos, 2007.

JAPIASSU, H. Introdução ao pensamento epistemológico. Rio de Janeiro: Francisco Alves, 1992.

. Questões epistemológicas. Rio de Janeiro: Imago, 1986.

MICELI, S. A condição do trabalho intelectual (comentários). In: CATANI, Afrânio M.; MARTINEZ, Paulo H. (Org.). Sete ensaios sobre o Collège de France. São Paulo: Cortez, 1999, p. 105-119.

NOGUEIRA, Maria A.; NOGUEIRA, Cláudio M. M. Bourdieu e a educação. Belo Horizonte: Autêntica, 2009.

ORTIZ, R. A sociologia de Pierre Bourdieu. São Paulo: Olho d'água, 2003.

Pierre Bourdieu a procura de uma sociologia da prática. In: . Ciências sociais e trabalho intelectual. São Paulo: Olho d'água, 2002, p. 149-174.

SILVA, H. R. da. Fragmentos da história intelectual: entre questionamentos e perspectivas. Campinas: Papirus, 2002.

VASCONCELOS, M. D. Pierre Bourdieu: A herança sociológica. Educação e Sociedade, Campinas, n. 78, p. 77-87, abr. 2002. 
WACQUANT, L. J. D. O legado sociológico de Pierre Bourdieu: duas dimensões e uma nota pessoal, Revista de Sociologia e Política, Curitiba, n.19, p. 95-110, nov. 2002.

VALLE, I. R. A obra do sociólogo Pierre Bourdieu: uma irradiação incontestável. Educação e Pesquisa, São Paulo, v. 33, n. 1, p. 117-134, jan./abr. 2007.

NéVIO de Campos: Pós-Doutor em História. Doutor em Educação. Professor no Programa de Pós-Graduação em Educação e no Programa de Mestrado em História da Universidade Estadual de Ponta Grossa, Paraná. Pesquisador Produtividade CNPq 2.

E-mail: ndoutorado@yahoo.com.br 
